\title{
Marijuana Use Episodes and Partner Intimacy Experiences: A Daily Report Study
}

Cannabis

2019, Volume 2 (1), 19-28

(C) Author(s) 2018

researchmj.org

DOI: 10.26828/cannabis.2019.01.002

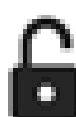

OPEN ACCESS

\section{Maria Testa ${ }^{1}$, Weijun Wang ${ }^{1}$, Jaye L. Derrick ${ }^{2}$, Kenneth E. Leonard $^{1}$}

${ }^{1}$ Research Institute on Addictions, University at Buffalo, Buffalo, NY, USA

${ }^{2}$ Department of Psychology, University of Houston, Houston, TX, USA

\section{ABSTRACT}

Although marijuana use has been linked to negative consequences for intimate relationships, an emerging literature suggests that under some circumstances it may have positive consequences. Couples who use substances together report better relationship functioning over time and may experience positive short-term outcomes. Using a sample of 183 heterosexual, frequent marijuana-using couples from the community, reporting over 30 consecutive days, we examined whether marijuana use episodes were associated temporally with reports of couple intimacy experiences within the next two hours. We used multilevel modeling, within an Actor Partner Interdependence Model (APIM) framework, modeling male and female outcomes simultaneously. Consistent with hypotheses, simultaneous marijuana use (male and female partners reported use at the same hour) increased the likelihood of an intimate experience for both men and women. However, we also found positive effects for Actor and Partner solo marijuana use on male and female reports of intimacy events. When analyses were limited to marijuana use episodes in which the respondent reported on presence of partner, we found that positive effects on intimate experiences were limited to marijuana use episodes in which partner was present; use without partner did not influence likelihood of intimacy. The robust positive effects of using marijuana with one's partner on intimacy events may serve to reinforce continued couple use and explain the positive effects of concordant substance use on relationship functioning over time.

Key words: cannabis, marijuana, relationship functioning, intimacy, daily diary

Although substance use within intimate couples has been linked to negative outcomes such as lower relationship satisfaction and elevated rates of aggression and divorce (Cunradi, Todd, \& Mair, 2015; Marshal, 2003; Yamaguchi \& Kandel, 1985), more recent perspectives consider that substance use may be a source of either pleasure or strain within relationships (Rodriguez \& Derrick, 2017). An emerging literature suggests that concordant use of alcohol and other drugs has positive consequences for relationship functioning (Homish \& Leonard, 2007; Smith et al., 2014). For example, drinking together and similar amounts has been shown to increase short-term couple functioning (Levitt \& Cooper, 2010) and long term satisfaction trajectories (Homish \& Leonard, 2005). Marijuana, the most commonly used illicit drug (Pearson, Liese, Dvorak, \& Marijuana Outcomes Study Team, 2017), may function similarly within couples. That is, shared or simultaneous use by intimate partners may contribute to positive couple interactions. However, very little is known about the immediate effects of marijuana use within couples. The present dyadic, daily report study considered the short term temporal effect of marijuana use episodes on subsequent experiences of partner intimacy over 30 days. 
Compared to the large database of knowledge regarding the acute effects of alcohol intoxication, much less is known about the acute effects of marijuana or its consequences for behavior. Marijuana users frequently report positive subjective consequences following use, including relaxation, happiness, and increased sexual pleasure (Green, Kavanagh, \& Young, 2003). Studies involving controlled marijuana administration also suggest positive subjective effects, particularly among more experienced users (Cooper \& Haney, 2014; Hart et al., 2010; Metrik, Kahler, McGeary, Monti, \& Rohsenow, 2011; Ramesh, Haney, \& Cooper, 2013). It is plausible that these feelings of well-being contribute to subsequent positive experiences, which in turn, reinforce and perpetuate subsequent marijuana use (Lee, Derefinko, Davis, Milich, \& Lynam, 2017). Although these effects have not been examined within couples, it is plausible that feelings of well-being after marijuana use lead the individual to experience or perceive - intimacy with his or her partner.

On the other hand, an emerging literature suggests that the impact of partner substance use within couples is more complicated. Couple substance use may be a source of pleasure or strain within the relationship (Rodriguez \& Derrick, 2017). An important determinant of its effects is whether the use is concordant or shared versus discrepant. For example, newlywed couples in which both partners used drugs (most commonly marijuana) reported higher relationship satisfaction at the time of marriage than couples in which only one partner used (Homish, Leonard, \& Cornelius, 2008). Similarly, couples with smaller discrepancies in their alcohol and tobacco use experienced smaller declines in relationship satisfaction over time relative to couples with larger discrepancies (Homish \& Leonard, 2007; Homish, Leonard, Kozlowski, \& Cornelius, 2009). Using longitudinal data from the present sample of marijuana using couples, we found a similar pattern using 4 time points, over 10 months. That is, at time points when the discrepancy in partner marijuana use frequency was greater than typical for the couple, relationship functioning was poorer (Testa, Wang, Derrick, \& Leonard, 2018). Corroborating these findings, Crane, Testa, Schlauch, and Leonard (2016) found that couples who were discrepant marijuana users (one partner used, the other did not) displayed more negative behavior in a conflict resolution paradigm than concordant users, even though they were not under the influence at the time. These studies suggest that concordant substance use helps to maintain relationship satisfaction, perhaps reflecting shared activities and values or shared positive experiences associated with substance use.

The studies reviewed above considered global relationship functioning associated with concordant versus discrepant substance use over time, and not immediate couple consequences. There is some evidence that drinking together, as opposed to apart, has positive consequences for short-term couple outcomes. In a sample of college student couples, Levitt and Cooper (2010) found that drinking with the partner had positive effects on next-day relationship functioning (e.g., feelings of closeness with one's partner) compared with drinking apart from one's partner or not drinking. Similar findings were observed in a sample of community couples: next day couple functioning was better following a day of drinking with partner compared with a day involving drinking apart from partner (Levitt, Derrick, \& Testa, 2014). It is plausible that using substances together leads to positive immediate consequences, such as shared emotional or sexual intimacy. In two daily report studies, sex was more likely to occur on days of marijuana use compared to days of no use (Fortenberry et al., 2005; Kerr, Washburn, Morris, Lewis, \& Tiberio, 2015). However, these studies involved individuals, without consideration of partner marijuana use, thus it is unknown whether both partners used marijuana prior to sex. To date, no published studies have considered whether couple marijuana use, shared or independent, leads in the short-term to increased partner intimacy.

\section{The Present Study}

The present study was designed to consider whether episodes of marijuana use, reported independently by male and female intimate partners, increase the short term likelihood of reporting an experience of partner intimacy. The sample consisted of heterosexual couples in which at least one partner used marijuana at least twice weekly. To the best of our knowledge, no prior study has considered this research question, thus we took an exploratory approach. Because several 
studies suggest that concordant or simultaneous substance use has different consequences than discrepant use or use without the partner, we considered the impact of these marijuana use events separately. Drawing on prior literature (Levitt \& Cooper, 2010), we hypothesized that simultaneous marijuana use by both partners would increase the likelihood that men and women would report experiencing intimacy in the next two hours compared with no marijuana use. The 2-hour window was chosen based on pharmacological studies suggesting that THC effects peak about 30 minutes after use and taper off after 2-3 hours (Grotenhermen, 2003). Similarly, we hypothesized that using marijuana in the presence, but not in the absence of one's partner, would increase the likelihood of subsequent intimacy experiences. We separately considered whether episodes of marijuana use by only one partner (not both) influence intimacy experiences but offered no hypothesis. Levitt and Cooper (2010) found that relationship intimacy increased the day after a couple drank together but found no advantage or disadvantage for drinking apart from partner compared with not drinking. On the other hand, greater discrepancies in substance use between partners have been associated with poorer couple functioning over time (Homish \& Leonard, 2007), suggesting that use by one partner and not the other may inhibit the occurrence of intimacy. It is also plausible that feelings of well-being following marijuana use contribute to increased experiences of intimacy with one's partner regardless of whether the partner is using. Use of the Actor Partner Interdependence Model (APIM, Kashy \& Snyder, 1995; Kenny, Kashy, \& Cook, 2006) allowed us to model the effects of one's own marijuana use on one's own reports of an intimate experience (Actor effects) as well as the effects of partner's use on one's own report (Partner effects).

\section{METHOD}

\section{Sample and Recruitment}

Participants included 183 married or cohabiting heterosexual couples in which at least one partner used marijuana at least twice per week. This minimum frequency was chosen to provide sufficient episodes of marijuana use to permit consideration of its temporal effects, within person, over 30 days. Men averaged 25.16 $(S D=3.07)$ and women $24.06(S D=3.09)$ years of age. Most couples were cohabiting $(84.2 \%)$ rather than married (15.8\%), with average length of marriage or cohabitation of 2.50 years (range $=$ $0.17-10.25, S D=2.19$ ). Most had completed at least some college $(70.5 \%$ of men, $79.3 \%$ of women, $24.0 \%$ currently enrolled) and were employed fullor part-time (84.2\% of men and $81.4 \%$ of women). Most self-identified as European-American (78.1\%), African-American (9.3\%), or mixed race $(6.6 \%)$. In the majority of couples $(127 / 183,69.4 \%)$ both partners reported using marijuana at least twice weekly.

Couples were recruited from a medium-sized metropolitan area in the Northeast primarily via Facebook ads (146/183, 79.8\%) or print ads in local free arts newspapers (22/183, 12.0\%) seeking couples who use marijuana; the rest were referred (15/183, 8.2\%). All couples were screened for eligibility by telephone. To be eligible, both partners were required to be between 18 and 30 years old, married or cohabiting for at least 6 months, and at least one partner had to use marijuana at least twice weekly with no intention to quit or seek treatment. Couples were excluded if either partner reported receiving psychiatric treatment, use of cocaine or stimulants, or pregnancy. Couples were also excluded if either reported experiencing intimate partner violence that caused fear for one's life or required medical care; they were provided referral information.

\section{Procedures}

Before beginning the 30-day reporting period, eligible couples completed a 90-minute in-person orientation. After study procedures were described to the couple, partners were escorted to private interview rooms to provide informed consent and complete computerized baseline questionnaires. Couples were then reunited for instruction on how to make independent, confidential reports on a secure web-based portal via smartphone. Most used phones provided for use during the study (277/366, 76.8\%), the rest used their own phones. Couples were instructed to initiate a marijuana report every time they were about to use marijuana and again when they finished. Similarly, they were to initiate conflict reports whenever they perceived a conflict or felt angry, irritated, or annoyed by the partner even if 
no argument occurred; conflict was not examined in the present analysis.

Participants were instructed to make a daily report each morning and study compensation was based on completion of this report. Text messages were sent at 7:00 AM and 12:00 PM each day reminding them to complete their daily report by 3:00 PM when the portal closed for the day. Whenever possible, staff contacted participants who failed to report by 3:00 PM to address any reporting problems and complete the daily report by telephone. Participants were sent weekly texts thanking them for participation and reminding them of monetary bonuses they had earned $(\$ 1$ per daily report, $\$ 10$ weekly bonus for completing at least 6/7 morning reports, $\$ 30$ for completing 4 weeks of reports, maximum of $\$ 100$ ). All study procedures were approved by the University Institutional Review Board. Compliance with daily reports was excellent. Of a possible 10,980 daily reports (30 days x 183 couples), men reported on $5,133 / 5,490$ days $(93.5 \%, M=28.05$ days, $S D=4.36$ ) and women on $5,253 / 5,490$ days $(95.7 \%, M=28.70$ days, $S D=3.09)$. Of these reports, 9,313/10,386 (89.7\%) were made on time.

\section{Measures}

Marijuana. Marijuana episodes were reported in two ways. First, participants were asked to make reports in real-time using a time-stamped, event-triggered report (up to 4 reports per day were permitted). However, to avoid missing any episodes of marijuana use, morning reports included assessment of whether at any time yesterday the respondent had used marijuana. If so, he or she was asked the time of use and whether that episode had already been reported. For marijuana episodes not already reported, an abbreviated set of follow-up questions was asked. All marijuana episode reports included the time of use and were included in temporal analyses, including 1,560 on-time reports and 6,075 next day reports.

Because we were interested in the effects of simultaneous use by both partners separate from the effects of use by one partner, we created three separate dichotomous marijuana variables to represent use in a given hour on a given day. When both partners independently reported a marijuana episode that occurred at the same hour, we considered that to represent an episode of simultaneous couple use. Marijuana episodes reported by one partner only, with no corresponding report of use by the other partner at the same hour, were considered as Actor- or Partner-only marijuana use episodes. At hours when no Actor, Partner, or simultaneous marijuana use was reported, use was coded as 0 .

Intimacy events. Intimacy experiences, the key dependent variable, were assessed on each morning report with the following question: "At any time yesterday, did you have an interaction or meaningful conversation with your partner that involved intimacy, love, caring, or support?" $(0=$ No; 1 = Yes). For each reported intimate experience, participants indicated the time it occurred, allowing us to determine the temporal ordering of marijuana use episodes and intimate experiences reported on the previous day.

\section{Analytic Strategy}

We examined whether the likelihood of reporting an episode of intimacy is a function of marijuana use in the previous 2 hours. We used multivariate multilevel modeling with three levels and random intercepts using Bayesian analysis within Mplus Version 7.4 (Gelman, Carlin, Stern, \& Rubin, 2014; Muthén \& Muthén, 2015; Muthén, Muthén, \& Asparouhov, 2016). Our unique, dyadic sample allowed us to use the Actor Partner Interdependence Model (APIM, Kashy \& Snyder, 1995; Kenny et al., 2006) to account for the effects of each person's own marijuana use on his or her report of an intimate experience (Actor paths) as well as the effects of each person's use on the partner's report of intimacy (Partner paths). At Level 1 (the hourly level), we entered as predictors: 1) simultaneous (Actor and Partner) marijuana use in the past 2 hours, 2) Actor-only marijuana use, and 3) Partner-only marijuana use. Male and female reports of intimacy events were modeled simultaneously. Level-1 marijuana use variables were binary and uncentered. At Level 1 we also included time of day ( $1=5$ PM-midnight, $0=$ all other hours) to control for unmeasured temporal effects (uncentered). At Level 2 (the daily level), we entered day of the study (1-30), grand mean centered, to account for the tendency for daily reports to decline over time (e.g., Testa, Wang, Derrick, \& Leonard, 2018). At Level 3 (the couple 
Table 1. Intimate Events as a Function of Actor, Partner, and Simultaneous Marijuana Use in the Previous 2 Hours

\begin{tabular}{|c|c|c|c|c|}
\hline \multirow[t]{2}{*}{ Variable } & \multicolumn{2}{|c|}{ Male report intimate event } & \multicolumn{2}{|c|}{ Female report intimate event } \\
\hline & Estimate (S.D.) & $95 \% \mathrm{CI}$ & Estimate (S.D.) & $95 \%$ CI \\
\hline Simultaneous marijuana use ${ }^{1}$ & $0.321(0.058) * * *$ & {$[0.206,0.434]$} & $0.279(0.057) * * *$ & {$[0.166,0.388]$} \\
\hline Actor only marijuana use & $0.251(0.032) * * *$ & {$[0.187,0.312]$} & $0.212(0.034) * * *$ & {$[0.144,0.278]$} \\
\hline Partner only marijuana use & $0.222(0.036) * * *$ & {$[0.151,0.291]$} & $0.176(0.032) * * *$ & {$[0.113,0.239]$} \\
\hline Evening vs. earlier time ${ }^{2}$ & $0.551(0.018) * * *$ & {$[0.515,0.587]$} & $0.521(0.017) * * *$ & {$[0.488,0.554]$} \\
\hline Day of the study ${ }^{3}$ & $-0.009(0.001) * * *$ & {$[-0.011,-0.007]$} & $-0.008(0.001) * * *$ & {$[-0.010,-0.006]$} \\
\hline $\begin{array}{l}\text { Actor total marijuana use } \\
\text { episodes }\end{array}$ & $-0.001(0.001)$ & {$[-0.003,0.001]$} & $-0.001(0.001)$ & {$[-0.002,0.001]$} \\
\hline $\begin{array}{l}\text { Partner total marijuana use } \\
\text { episodes }\end{array}$ & $0.000(0.001)$ & {$[-0.002,0.002]$} & $-0.001(0.001)$ & {$[-0.002,0.001]$} \\
\hline $\begin{array}{l}\text { Total simultaneous } \\
\text { marijuana use episodes }\end{array}$ & $-0.002(0.002)$ & {$[-0.006,0.002]$} & $0.000(0.002)$ & {$[-0.004,0.004]$} \\
\hline Actor total intimate events & $0.034(0.002) * * *$ & {$[0.032,0.037]$} & $0.031(0.001) * * *$ & {$[0.029,0.034]$} \\
\hline Partner total intimate events & $-0.001(0.001)$ & {$[-0.003,0.002]$} & $-0.002(0.001)$ & {$[-0.004,0.001]$} \\
\hline
\end{tabular}

Note. ${ }^{* * *} p<.001,{ }^{* *} p<.01,{ }^{*} p<.05$. Male and female outcomes were modeled simultaneously. ${ }^{1}$ Both partners reported marijuana use at the same hour. ${ }^{2}$ Time $(0=$ Hour 1 to Hour $16 ; 1=$ Hour 17 to Hour 24).

level), we controlled for total number of simultaneous and solo marijuana episodes over 30 days, allowing us to distinguish within-person effects of marijuana use from between-person effects. We also included total number of intimate experiences, to account for between-person differences in the tendency to report intimacy. Level-3 variables were grand mean centered (Enders \& Tofighi, 2007).

\section{RESULTS}

\section{Event Reports}

Intimacy events were reported 4,887 times by the 366 participants over 30 days of reports, with nearly all couples $(98.9 \%)$ reporting at least one such event. Intimacy experiences were more likely to be reported after $5 \mathrm{PM}$ than before $5 \mathrm{PM}, \chi^{2}(1$, $n=9,294)=143.700, p<.001$. Women reported significantly more intimacy experiences $(2,598$, mean $=14.40$, range $=0-30, S D=7.80)$ than men $($ mean $=12.89$, range $=0-29, S D=8.25), \chi^{2}(1, n=$ $10,301)=23.728, p<.001$. On $1,618(29.5 \%)$ days, both partners reported an intimacy event, on 1,784 (32.5\%) days, neither did, and on 2,088 (38.0\%) days, one partner but not the other reported an intimacy event.

A total of 7,529 marijuana use episodes were reported on 6,324 days by the 366 participants.
Men reported more marijuana episodes and days of marijuana use $(4,017$ events, mean $=18.46$ marijuana use days, range $=0-30, S D=9.45$ ) than women $(3,512$ events, mean $=16.10$ marijuana use days, range $=0-30, S D=10.20), t(10,978)=$ $12.232, p<.001$. There were 1,640 episodes of simultaneous couple marijuana use, that is, both male and female partner reported use at the same hour. In addition, there were 3,196 episodes of male only use, and 2,693 episodes of female only marijuana use (i.e., no corresponding marijuana use by the partner at the same hour). Most couples $(140 / 183,76.5 \%)$ reported both solo and simultaneous marijuana use events.

Temporal Effects of Simultaneous and Solo Marijuana Use Episodes on Intimacy Events

Table 1 displays the effects of simultaneous and solo marijuana use on the occurrence of male and female intimacy events in the next 2 hours. Consistent with our hypothesis, simultaneous marijuana use (use by both partners at the same hour) significantly increased the likelihood of intimacy reports by both men and women compared with no marijuana use. However, we also observed significant positive effects of Actor and Partner solo marijuana use on men's and women's experiences of intimacy. Men and women were more likely to report an intimacy experience within 2 hours of using marijuana in the absence 
Table 2. Intimate Events as a Function of Marijuana Use in Presence of Partner, Previous 2 Hours

\begin{tabular}{|c|c|c|c|c|}
\hline \multirow[t]{2}{*}{ Variable } & \multicolumn{2}{|c|}{ Male report intimate event } & \multicolumn{2}{|c|}{ Female report intimate event } \\
\hline & Estimate (S.D.) & $95 \% \mathrm{CI}$ & Estimate (S.D.) & $95 \% \mathrm{CI}$ \\
\hline $\begin{array}{l}\text { Actor marijuana use, partner } \\
\text { present }\end{array}$ & $0.302(0.041) * * *$ & {$[0.221,0.381]$} & $0.190(0.042) * * *$ & {$[0.106,0.271]$} \\
\hline $\begin{array}{l}\text { Partner marijuana use, } \\
\text { partner present }\end{array}$ & $0.122(0.045) * *$ & {$[0.033,0.208]$} & $0.113(0.044) *$ & {$[0.026,0.197]$} \\
\hline $\begin{array}{l}\text { Actor marijuana use, partner } \\
\text { not present }\end{array}$ & $-0.002(0.077)$ & {$[-0.157,0.149]$} & $-0.064(0.104)$ & {$[-0.281,0.128]$} \\
\hline $\begin{array}{l}\text { Partner marijuana use, } \\
\text { partner not present }\end{array}$ & $-0.158(0.119)$ & {$[-0.400,0.062]$} & $0.020(0.073)$ & {$[-0.128,0.158]$} \\
\hline Even & $0.565(0.018) * * *$ & {$[0.529,0.601]$} & $0.531(0.017) * * *$ & {$[0.498,0.564]$} \\
\hline Day c & $-0.009(0.001) * * *$ & {$[-0.011,-0.007]$} & $-0.008(0.001) * * *$ & {$[-0.010,-0.007]$} \\
\hline $\begin{array}{l}\text { Actor total marijuana use } \\
\text { episodes with partner present }\end{array}$ & $0.000(0.001)$ & {$[-0.003,0.002]$} & $-0.001(0.001)$ & {$[-0.003,0.002]$} \\
\hline $\begin{array}{l}\text { Partner total marijuana use } \\
\text { episodes with partner present }\end{array}$ & $0.000(0.001)$ & {$[-0.003,0.002]$} & $0.000(0.001)$ & {$[-0.003,0.003]$} \\
\hline $\begin{array}{l}\text { Actor total marijuana use } \\
\text { episodes, partner not present }\end{array}$ & $-0.003(0.002)$ & {$[-0.006,0.001]$} & $-0.002(0.003)$ & {$[-0.007,0.003]$} \\
\hline $\begin{array}{l}\text { Partner total marijuana use } \\
\text { episodes, partner not present }\end{array}$ & $0.000(0.003)$ & {$[-0.005,0.006]$} & $0.000(0.001)$ & {$[-0.003,0.002]$} \\
\hline Actor & $0.034(0.001) * * *$ & {$[0.032,0.037]$} & $0.031(0.002) * * *$ & {$[0.028,0.034]$} \\
\hline Partner total intimate events & $-0.001(0.001)$ & {$[-0.004,0.002]$} & $-0.002(0.001)$ & {$[-0.004,0.001]$} \\
\hline
\end{tabular}

Note. ${ }^{* * *} p<.001,{ }^{* *} p<.01,{ }^{*} p<.05$. Male and female outcomes were modeled simultaneously. ${ }^{1}$ Time $(0$ $=$ Hour 1 to Hour 16; 1 = Hour 17 to Hour 24). Based on 4,870 marijuana use reports with data on partner presence versus absence at time of use.

of use by partner (Actor effect) compared to no marijuana use. They were also more likely to report an intimacy experience within 2 hours of the partner using marijuana in the absence of their own use (Partner effect) compared to no use. Results were obtained after accounting for the effects of time of day, since as expected, intimate events were more likely to occur in the evening. Results also accounted for the positive Level 3 effects of number of intimate events reported; individuals who reported more intimate events over the 30 days were more likely to report an event in a given hour. Total episodes of simultaneous and solo marijuana use were not associated with the likelihood of reporting an intimacy event in a given hour.

Our classification of simultaneous marijuana use required that both partners report use at the same hour. Small errors in recall of the hour would result in classification of a simultaneous episode as two solo episodes, potentially inflating the positive impact of the latter. To address this potential weakness, we classified an episode as simultaneous use if partners reported using at the same hour or +/- 1 hour (e.g., $6 \mathrm{PM}$ and $7 \mathrm{PM}$ would be classified as simultaneous). Results using this broader classification were identical to those depicted in Table 1; that is, we still found positive effects of simultaneous and of solo Actor and Partner marijuana use. We also repeated the analysis replacing the 2 hour window with 1 hour and 3 hour windows and found identical results. Simultaneous and solo marijuana use increased the likelihood of intimacy experiences for men and women within 1, 2, and 3 hours of use.

Temporal Effects of Using Marijuana in Presence of Partner vs. Without Partner

As an alternative way of considering the impact of simultaneous versus solo marijuana use, we conducted a second analysis using individual's reports of whether the partner was present at the time of his or her marijuana use. For 4,870/7,529 (64.7\%) marijuana reports, we had responses to a question regarding whether one's partner was present at the time of marijuana use. The majority of marijuana 
episodes took place when the partner was present and using marijuana $(3,019 / 4,870,62.0 \%)$ or present but not using $(564 / 4,870,11.6 \%)$. In a smaller number of marijuana events, use took place when the partner was not present $(1,287 / 4,870,26.4 \%)$. We used these reports to create two dichotomous variables: marijuana use in a given hour with partner present and marijuana use in a given hour with partner not present. Hours with no marijuana use were coded 0 .

Within the APIM framework, we considered the impact of Actor marijuana use, with and without presence of the partner, and the impact of Partner marijuana use, with and without presence of the partner. Results of this analysis, displayed in Table 2, show positive Actor and Partner effects associated with using marijuana in the presence of the partner for both men and women. For example, Laura is more likely to report an intimacy event within 2 hours of using marijuana in Mike's presence (an Actor effect) than when she doesn't use marijuana. Laura is also more likely to report an intimacy event within 2 hours of Mike reporting marijuana use in Laura's presence (a Partner effect). However, marijuana use when the partner was not present neither increased nor decreased the likelihood of experiencing intimacy relative to no marijuana use.

\section{DISCUSSION}

Using data from an intensive daily report study of frequent marijuana-using couples, we found evidence that marijuana use is associated with increased experiences of intimacy, love, caring or support with one's intimate partner in the next two hours. We had hypothesized, consistent with prior studies of drinking together versus drinking apart (Levitt \& Cooper, 2010; Levitt et al., 2014) that using marijuana with one's partner would be particularly likely to increase intimacy. Using two different methods of analysis, we found robust support for the positive effects of using marijuana at the same time as or in the presence of one's partner on subsequent experiences of intimacy. Findings were identical for both male and female intimate partners. Results replicate and extend prior findings, which have shown positive effects of partners drinking together (versus drinking apart) on couple functioning the next day (Levitt et al., 2014) and over time (Homish \& Leonard, 2005). Our study revealed that positive effects of marijuana on intimacy were observable within 1,2 , and 3 hours of use. These intimacy experiences may be the mechanism that contributes to better couple functioning the next day and over time.

We also found some evidence that marijuana use by either partner in the absence of use by the other also increased reports of intimacy in the next few hours. This effect may reflect feelings of well-being and relaxation following marijuana use (Green et al., 2003), which contribute to the experience of intimacy with one's partner. However, this was not simply an Actor effect but rather a Partner effect as well: men and women were more likely to report an intimacy experience within 2 hours of their partner (only) using marijuana, possibly reflecting the effects of the partner's positive affect. The partner effects are particularly striking given that these involve independent reports from two individuals, and partner effects are typically weaker than actor effects (Orth, 2013). It will be important to replicate these unique findings since it is possible that positive effects of solo use are inflated by our method of classification. That is, correct classification as an episode of simultaneous use requires independent reporting from both partners. If one partner fails to record such an episode or records the wrong hour, the use of the other partner will be incorrectly classified as solo use.

On the other hand, when we analyzed data using individual's reports of partner presence at the time of marijuana use, we failed to find an effect of using marijuana when partner was not present on subsequent intimacy. Rather, using marijuana without partner present had no effect, positive or negative, on subsequent reports of intimacy, a pattern consistent with Levitt and Cooper (2010). Although substance use by only one partner is thought to represent a potential source of stress and conflict for the non-using partner (Rodriguez, Neighbors, \& Knee, 2014), we found no evidence that use without partner had detrimental effects on intimacy. However, this sample consisted primarily of couples in which both partners use marijuana frequently and often together; these couples may not be troubled by occasional independent episodes of use. 


\section{Limitations}

Dyadic, daily report data provide a rich and unique view of daily relationship events, permitting examination of the effects of both partners' marijuana use on couple outcomes. Nonetheless, there are potential limitations associated with these data. Although compliance with daily reports was excellent, compliance with event-triggered marijuana reports was not. Many marijuana reports were made retrospectively, the next morning. As a result, individuals may fail to report every instance of marijuana use or may misreport the time of use. To mitigate against some of these concerns, we considered the effects of marijuana use with partner using different methods and found very similar results, increasing confidence that the positive effects of marijuana use with partner are robust. Intimacy was defined broadly - which may be viewed as a strength or a weakness - and we have no specific information as to what type of intimacy was involved. It will be important for future research to gather more detailed information about these experiences and distinguish between different types (e.g., sexual versus emotional intimacy). Importantly, results were obtained using a sample of couples who were recruited because of their frequent but not problematic marijuana use and it is not known how well our findings would generalize to other samples. Couples in which one partner but not the other is a heavy or problematic user may not experience the same positive effects of marijuana use and may experience negative effects associated with unreciprocated use. In addition, the sample was young, and primarily White, employed, and recruited through Facebook; findings may not generalize to other samples of marijuana-using couples.

\section{Conclusions and Implications}

The two methods of analyses reveal robust positive effects of marijuana use with partner on subsequent intimacy experiences, with some evidence for positive effects of solo use as well. In earlier analyses using these data, we also found temporal effects of marijuana use on partner conflict within the next two hours, although these effects were modest (Testa, Wang, Derrick, \& Leonard, 2018). Although at first glance these results appear inconsistent, it is certainly plausible that couple marijuana use episodes may increase the odds of either positive or negative outcomes occurring depending on daily, situational factors. It is also possible that some couples are more likely to experience positive versus negative outcomes. Because the positive effects of marijuana are particularly strong, they are probably more apparent to users than the more modest effects on partner conflict, reinforcing positive marijuana expectancies and encouraging use within the couple. These shortterm effects of concordant marijuana use on couple intimacy may help to explain the longerterm positive effects of concordant substance use on couple functioning that have been observed (Homish \& Leonard, 2005; 2007; Testa, Wang, Derrick, \& Leonard, 2018). On the other hand, the positive association between marijuana and couple intimacy has implications for treatment to reduce or end marijuana use. It is important for treatment providers to recognize that when increased couple intimacy is perceived as a desirable outcome of marijuana use, treatment may be more difficult because it interferes with the positive marijuana effects previously enjoyed (Rohrbaugh et al., 2001).

\section{REFERENCES}

Cooper, Z. D., \& Haney, M. (2014). Investigation of sex-dependent effects of cannabis in daily cannabis smokers. Drug and Alcohol Dependence, $\quad 136, \quad 85-91$. doi:10.1016/j.drugalcdep.2013.12.013

Cunradi, C. B., Todd, M., \& Mair, C. (2015). Marijuana use, and smoking and intimate partner violence: Results from the California community health study of couples. Journal of Drug Education, 45(2), 73-95. doi:10.1177/0047237915608450

Crane, C. A., Testa, M., Schlauch, R. C., \& Leonard, K. E. (2016). The couple that smokes together: Dyadic marijuana use and relationship functioning during conflict. Psychology of Addictive Behaviors, 30(6), 686693. doi:10.1037/adb0000198

Enders, C. K., \& Tofighi, D. (2007). Centering predictor variables in cross-sectional multilevel models: A new look at an old issue. Psychological Methods, 12(2), 121-138. doi:10.1037/1082-989X.12.2.121 
Fortenberry, J. D., Temkit, M., Tu, W., Graham, C., Katz, B. P., \& Orr, D. P. (2005). Daily mood, partner support, sexual interest, and sexual activity among adolescent women. Health Psychology, 24(3), 252-257. doi:10.1037/02786133.24.3.252

Gelman, A., Carlin, J. B., Stern, H. S., \& Rubin, D. B. (2014). Bayesian data analysis (Vol. 2). Boca Raton, FL: Chapman \& Hall/CRC.

Green, B., Kavanagh, D., \& Young, R. (2003). Being stoned: A review of self-reported cannabis effects. Drug and Alcohol Review, $22(4)$, 453-460. doi:10.1080/09595230310001613976

Grotenhermen, F. (2003). Pharmacokinetics and pharmacodynamics of cannabinoids. Clinical Pharmacokinetics, 42(4), 327-360.

Hart, C. L., Ilan, A. B., Gevins, A., Gunderson, E. W., Role, K., Colley, J., \& Foltin, R. W. (2010). Neurophysiological and cognitive effects of smoked marijuana in frequent users. Pharmacology, Biochemistry and Behavior, 96(3), 333-341. doi:10.1016/j.pbb.2010.06.003

Homish, G. G., \& Leonard, K. E. (2005). Marital quality and congruent drinking. Journal of Studies on Alcohol, 66(4), 488-496. doi:10.15288/jsa.2005.66.488

Homish, G. G., \& Leonard, K. E. (2007). The drinking partnership and marital satisfaction: The longitudinal influence of discrepant drinking behavior. Journal of Consulting and Clinical Psychology, 75(1), 43-51. doi:10.1037/0022-006X.75.1.43

Homish, G. G., Leonard, K. E., \& Cornelius, J. R. (2008). Illicit drug use and marital satisfaction. Addictive Behaviors, 33(2), 279291. doi:10.1016/j.addbeh.2007.09.015

Homish, G. G., Leonard, K. E., Kozlowski, L. T., \& Cornelius, J. R. (2009). The longitudinal association between multiple substance use discrepancies and marital satisfaction. Addiction, 104(7), 1201-1209. doi:10.1111/j.1360-0443.2009.02614.x

Kashy, D. A., \& Snyder, D. K. (1995). Measurement and data analytic issues in couples research. Psychological Assessment, 7(3), 338-348. doi:10.1037/1040-3590.7.3.338

Kenny, D. A., Kashy, D. A., \& Cook, W. L. (2006). Dyadic data analysis. New York, NY: Guilford Press.
Kerr, D. C. R., Washburn, I. J., Morris, M. K., Lewis, K. A. G., \& Tiberio, S. S. (2015). Eventlevel associations of marijuana and heavy alcohol use with intercourse and condom use. Journal of Studies on Alcohol and Drugs, 76(5), 733-737. doi:10.15288/jsad.2015.76.733

Lee, C. A., Derefinko, K. J., Davis, H. A., Milich, R., \& Lynam, D. R. (2017). Cross-lagged relations between motives and substance use: Can use strengthen your motivation over time? Drug and Alcohol Dependence, 178, 544550. doi:10.1016/j.drugalcdep.2017.05.027

Levitt, A., \& Cooper, M. L. (2010). Daily alcohol use and romantic relationship functioning: Evidence of bidirectional, gender-, and context-specific effects. Personality and Social Psychology Bulletin, 36(12), 1706-1722. doi:10.1177/0146167210388420

Levitt, A., Derrick, J. L., \& Testa, M. (2014). Relationship-specific alcohol expectancies and gender moderate the effects of relationshipdrinking contexts on daily relationship functioning. Journal of Studies on Alcohol and Drugs, 75(2), 269-278.

Marshal, M. P. (2003). For better or for worse? The effects of alcohol use on marital functioning. Clinical Psychology Review, 23(7), 959-997. doi:10.1016/j.cpr.2003.09.002

Metrik, J., Kahler, C. W., McGeary, J. E., Monti, P. M., \& Rohsenow, D. J. (2011). Acute effects of marijuana smoking on negative and positive affect. Journal of Cognitive Psychotherapy, 25(1), 31-46. doi:10.1891/0889-8391.25.1.31

Muthén, B. O., Muthén, L. K., \& Asparouhov, T. (2016). Regression and mediation analysis using Mplus. Los Angeles, CA: Muthen \& Muthen.

Muthén, L. K., \& Muthén, L. K. (2015). Mplus Users' Guide: Seventh Edition. Los Angeles, CA: Muthen \& Muthen.

Orth, U. (2013). How large are actor and partner effects of personality on relationship satisfaction? The importance of controlling for shared method variance. Personality and Social Psychology Bulletin, 39, 359-372. doi:10.1177/0146167213492429

Pearson, M. R., Liese, B. S., Dvorak, R. D., \& Marijuana Outcomes Study Team (2017). College student marijuana involvement: Perceptions, use, and consequences across 11 college campuses. Addictive Behaviors, 66, 8389. doi:10.1016/j.addbeh.2016.10.019 
Ramesh, D., Haney, M., \& Cooper, Z. D. (2013). Marijuana's dose-dependent effects in daily marijuana smokers. Experimental and Clinical Psychopharmacology, 21(4), 287-293. doi:10.1037/a0033661

Rodriguez, L. M., \& Derrick, J. L. (2017). Breakthroughs in understanding addiction and close relationships. Current Opinion in Psychology, 13, 115-119. doi:10.1016/j.copsyc.2016.05.011

Rodriguez, L. M., Neighbors, C., \& Knee, C. R. (2014). Problematic alcohol use and marital distress: An interdependence theory perspective. Addiction Research \& Theory, $22(4)$, 294-312. doi:10.3109/16066359.2013.841890

Rohrbaugh, M. J., Shoham, V., Trost, S., Muramoto, M., Cate, R. M., \& Leischow, S. (2001). Couple dynamics of change-resistant smoking: Toward a family consultation model. Family Process, 40(1), 15-31. doi:10.1111/j.1545-5300.2001.4010100015.x

Smith, P. H., Homish, G. G., Collins, R. L., Giovino, G. A., White, H. R., \& Leonard, K. E. (2014). Couples' marijuana use is inversely related to their intimate partner violence over the first 9 years of marriage. Psychology of Addictive Behaviors, 28(3), 734-742. doi:10.1037/a0037302
Testa, M., Derrick, J. L., Wang, W., Leonard, K. E., Kubiak, A., Brown, W. C., \& Collins, R. L. (2018). Does marijuana contribute to intimate partner aggression? Temporal effects in a community sample of marijuana-using couples. Journal of Studies on Alcohol and Drugs, $\quad 79, \quad 432-440$. https://doi.org/10.15288/jsad.2018.79.432

Testa, M., Wang, W., Derrick, J. L., \& Leonard, K. E. (2018). Marijuana use by intimate partners: Does discrepant use impair relationship functioning? Psychology of Addictive Behaviors. $\quad 32(4), \quad 475-484$. http://dx.doi.org/10.1037/adb0000357

Yamaguchi, K., \& Kandel, D. B. (1985). On the resolution of role incompatibility: A life event history analysis of family roles and marijuana use. American Journal of Sociology, 90(6), 1284-1325. doi:10.1086/228211

Funding: This research was supported by grant R01DA033994 from the National Institute on Drug Abuse to Maria Testa.

Copyright: (C) 2018 Authors et al. This is an open access article distributed under the terms of the Creative Commons Attribution License, which permits unrestricted use, distribution, and reproduction, provided the original author and source are credited, the original sources is not modified, and the source is not used for commercial purposes.

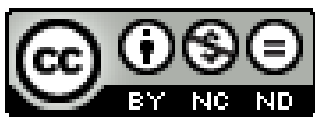

